\title{
Prevalence and Clinical Predictors of Right Ventricular Dysfunction in Patients with Chronic Right Ventricular Pacing
}

Jumsuk Ko, MD, PhD; Nam Ho Kim, $\mathrm{MD}, \mathrm{PhD}$

Department of Cardiology Wonkwang University of Medicine \& Hospital, Iksan, Republic of Korea
Received: April 5, 2016

Revision Received: June 22, 2016

Accepted: June 29, 2016

Correspondence: Jumsuk Ko, MD, PhD

Department of Cardiology Wonkwang University

of Medicine \& Hospital, 895, Muwang-ro, Iksan-

si, Jeollabuk-do 54538, Republic of Korea

Tel: +82-63-859-2526 Fax: +82-63-852-8480

E-mail: nemor@daum.net

Copyright (C) 2016 The Official Journal of Korean Heart Rhythm Society Editorial Board and MMK

Communications Limited

\section{ABSTRACT}

Background and Objectives: Numerous clinical studies have demonstrated chronic right ventricular (RV) pacing induced left ventricular (LV) dyssynchrony and LV systolic dysfunction in patients with permanent pacemaker. However, only a limited number of studies have focused on RV dysfunction. We sought to determine the prevalence and identify the clinical predictors of RV dysfunction in patients with chronic RV pacing.

Subjects and Methods: We enrolled 72 patients (mean age $72.7 \pm 11.1$ years, men $36.1 \%$ ) who underwent permanent pacemaker implantation without RV dysfunction in baseline examination. Baseline clinical characteristics, laboratory data, echocardiographic parameters and pacing profiles were assessed. Follow up 2-dimentional echocardiography was used to identify the presence of RV dysfunction.

Results: We divided patients based on the criteria of either presence or absence of RV dysfunction, where RV dysfunction is defined as decreased tricuspid annulus systolic velocity $(<11 \mathrm{~cm} / \mathrm{sec})$ in tissue Doppler image. Sixteen patients (22.2\%) in our study showed meaningful RV dysfunction. Patients with RV dysfunction had lower LV ejection fraction $(57.5 \pm 10.8 \%$ versus $64.6 \pm 9.1 \%, p<0.05)$ and higher B-type natriuretic peptide (BNP) levels $(700.3 \pm 152.9 \mathrm{pg} / \mathrm{mL}$ versus $329.4 \pm 332.4 \mathrm{pg} / \mathrm{mL}, p<0.05)$ compared to patients without RV dysfunction. Implantation of VVI type pacemaker was associated with presence of RV dysfunction (81.3\% versus 33.3\%, $p<0.05$ ). Higher cumulative ratio of total RV pacing was associated with increased tendency for RV dysfunction. No statistically significant correlation was observed between the groups $(70.7 \pm 13.2 \%$ in RV dysfunction group, $61.7 \pm 38.3 \%$ in non-RV dysfunction group, $p=0.094$ ).

Conclusion: In this study, meaningful proportion of patients showed chronic RV pacing induced RV dysfunction. RV dysfunction was associated with lower LV systolic function, higher BNP level and VVI type pacemaker.

Key Words: -Ventricular Dysfunction, Right Chronic Right Ventricular Pacing 


\section{Introduction}

Cardiac pacing at right ventricular (RV) apex is an effective and well-established therapy for patients with sick sinus syndrome and atrioventricular conduction disturbance. In most cases, permanent pacing is well tolerated without serious complications. However, increasing number of studies indicate association of conventional RV pacing with left ventricular dysfunction and unfavorable clinical outcomes. ${ }^{1.2}$ Cardiac resynchronization therapy has been proposed to attenuate left ventricular (LV) systolic dysfunction. ${ }^{3}$ In contrast, it has not been thoroughly investigated whether RV pacing could influence RV function.

The aim of this study was to assess the prevalence and identify the clinical predictors of RV dysfunction in patients with permanent pacemaker.

\section{Subjects and Methods}

\section{Patients}

This study enrolled 72 consecutive patients who had class I indication for permanent pacemaker based on the American Heart Association (AHA) guideline. Pacemaker implantation was performed under local anesthesia with the pacing lead inserted from the right or left subclavian vein. Atrial leads were positioned at the right atrial appendage and the ventricular leads were positioned at the right ventricular apex.

All enrolled patients were clinically evaluated and received laboratory examination at the time of inclusion. Standard echocardiography was performed at baseline and during 1 year follow up. Patients with RV dysfunction at baseline echocardiography were excluded. We analyzed pacemaker parameters and cumulative RV pacing ratio within 6 months of last follow up.

\section{Echocardiographic assessment}

Standard echocardiography was performed using Vivid ${ }^{\mathrm{TM}} 7$ (GE, Milwaukee, USA) echocardiograph with a $2.5 \mathrm{MHz}$ phased array transducer under simultaneous electrocardiogram monitoring. Two-dimensional images were acquired with a frame rate of $50 \mathrm{~Hz}$. Standard echocardiographic views were obtained at baseline and follow up images analyzed offline with commercially available software (EchoPAC ${ }^{\mathrm{TM}}$, GE Vingmed). LV ejection fraction was calculated based on Simpson's modified single plane method using the apical 4-chamber view. Values above 50\% were considered normal. Functional assessment of the RV included conventional two dimensional and M-mode measurements, as well as tissue Doppler derived data. Impaired RV systolic function was defined as values less than $11 \mathrm{~cm} / \mathrm{sec}$ of Doppler derived tricuspid lateral annular systolic velocity ( $S$ ' velocity).

\section{Statistical analysis}

Continuous variables are expressed as mean \pm standard deviation. Continuous variables were analyzed by Student's $t$-test and categorical data compared using chi square test. $p<0.05$ was considered statistically significant. Correlation of two continuous variables were analyzed by means of $t$ linear regression and expressed by Pearson's $r$ coefficient. Analyses were carried out using a standard statistical software program (SPSS version 20, SPSS Inc., Chicago, IL, USA)

\section{Results}

Among 72 consecutive patients (mean age $72.7 \pm 11.1$ years, male 36.1\%) who were enrolled for study, 16 patients showed new onset RV dysfunction as assessed by echocardiography. There were no statistically significant differences in age, gender and co-morbidity in patients with or without RV dysfunction (Table 1). Patients with RV dysfunction had higher initial serum B-type natriuretic peptide (BNP) level $(700.3 \pm 152.9 \mathrm{pg} / \mathrm{mL}$ in patients with RV dysfunction, $329.4 \pm 332.4 \mathrm{pg} / \mathrm{mL}$ in patients without $\mathrm{RV}$ dysfunction, $p<0.05)$ compared to patients without $\mathrm{RV}$ dysfunction (Table 2). Presence of RV dysfunction was associated with non-atrioventricular sequential type pacing mode $(81.3 \%$ in patients with RV dysfunction, 33.3\% in patients without RV dysfunction, $p<0.05)$. Cumulative ratio of total $R V$ pacing did not show statistically significant difference between the two groups (70.7 $\pm 13.2 \%$ in RV dysfunction group, $61.7 \pm 38.3 \%$ in non-RV dysfunction group, $p>0.05$ ). Table 2 depicts echocardiography parameters which revealed no statistically significant difference 
Table 1. Baseline clinical characteristics of patients

\begin{tabular}{|c|c|c|c|}
\hline & $\begin{array}{l}\text { Patients with right ventricular } \\
\text { dysfunction }(\mathrm{n}=16)\end{array}$ & $\begin{array}{l}\text { Patients without right ven- } \\
\text { tricular dysfunction }(\mathrm{n}=66)\end{array}$ & $P$-value \\
\hline Age (years) & $70.7 \pm 13.2$ & $70.9 \pm 13.4$ & 0.996 \\
\hline Male, $n(\%)$ & $3(18.7)$ & $27(40.9)$ & 0.117 \\
\hline Hypertension, n (\%) & $11(68.7)$ & $42(63.6)$ & 0.582 \\
\hline Diabetes mellitus, n (\%) & $5(31.2)$ & $17(25.7)$ & 0.440 \\
\hline Hyperlipidemia, n (\%) & $4(25)$ & $8(12.1)$ & 0.243 \\
\hline Ischemic heart disease, $n$ (\%) & $1(6.25)$ & $5(7.5)$ & 0.646 \\
\hline Cerebrovascular disease, $n(\%)$ & $3(18.7)$ & $11(16.6)$ & 0.650 \\
\hline Atrial fibrillation in initial rhythm diagnosis, $\mathrm{n}(\%)$ & $3(25)$ & $4(9.5)$ & 0.175 \\
\hline PPM indication, $n(\%)$ & & & 0.175 \\
\hline Sinus node dysfunction & $8(50)$ & $36(54.5)$ & \\
\hline AV node conduction disorder & $8(50)$ & $30(55.5)$ & \\
\hline permanent pacemaker mode, $n(\%)$ & & & 0.035 \\
\hline VVI & $13(81.3)$ & $22(33.3)$ & \\
\hline DDD, VDD & $3(18.7)$ & $44(66.7)$ & \\
\hline Cumulative right ventricular pacing, $n$ (\%) & $70.7 \pm 13.2$ & $61.7 \pm 38.3$ & 0.094 \\
\hline
\end{tabular}

$\mathrm{AV}$, atrioventricular; PPM, permanent pacemaker.

between two groups except LV ejection fraction $(57.5 \pm 10.8 \%$ versus $64.6 \pm 9.1 \%, p=0.05)$. After multivariate analysis, VVI type pacing mode and high serum BNP level were considered as clinical predictors of RV dysfunction (Table 3).

\section{Discussion}

In the present study, we demonstrate that a notable proportion of patients with permanent pacemaker had RV dysfunction and this was associated with lower LV ejection fraction, nonsequential $\mathrm{AV}$ pacing mode and elevated serum BNP levels.

Numerous previous reports have suggested that ventricular pacing, particularly, right ventricular apical pacing caused left ventricular dyssynchrony. ${ }^{1,2}$ In detail, pacing from RV apex pacing leads to abnormal sequence of ventricular depolarization, manifested as a widened QRS with left bundle branch block
(LBBB). Therefore, heterogeneous electrical activation of myocardial segment causes temporal difference of contraction between interventricular septum and the lateral wall of $\mathrm{LV}^{4,5}$

This abnormal ventricular depolarization consequently leads to unfavorable mechanical changes in ventricles ultimately resulting in reduced stroke volume and a compensatory enlargement of the ventricular chamber. ${ }^{67}$ These hypotheses were supported by experimental models demonstrating acute reduction of $L V$ systolic volume with $\mathrm{LBBB}$ and normalized LV function with septal pacing. ${ }^{8}$ Furthermore, LV dyssynchrony by itself causes structural remodeling of myocardial tissue. A previous published article demonstrates the effects of long term RV apical pacing induced myocardial perfusion defects on nuclear studies. ${ }^{9}$ The magnitude of these defects is proportional to the duration of pacing and degree of LV dysfunction. In-vivo studies have shown that myofibrillar disarray, ${ }^{10}$ redistribution of myocardial fiber strain 
Table 2. Echocardiographic and laboratory data

\begin{tabular}{|c|c|c|c|}
\hline & $\begin{array}{l}\text { Patients with right ventricular } \\
\text { dysfunction }(n=16)\end{array}$ & $\begin{array}{l}\text { Patients without right ven- } \\
\text { tricular dysfunction }(n=66)\end{array}$ & $P$-value \\
\hline Left ventricular ejection fraction (\%) & $57.5 \pm 10.8$ & $64.8 \pm 9.1$ & 0.050 \\
\hline Left ventricular end diastolic dimension (mm) & $51.8 \pm 7.5$ & $63.3 \pm 7.9$ & 0.580 \\
\hline Left atrial diameter (mm) & $36.3 \pm 16.3$ & $31.0 \pm 17.3$ & 0.348 \\
\hline Mitral E/E' ratio & $12.9 \pm 5.6$ & $14.1 \pm 7.2$ & 0.616 \\
\hline Tricuspid regurgitation, n (\%) & $5(31.2)$ & $14(21.2)$ & 0.239 \\
\hline Follow-up left ventricular ejection fraction (\%) & $50.7 \pm 14.2$ & $55.0 \pm 17.6$ & 0.103 \\
\hline Follow-up left ventricular end diastolic dimension (mm) & $56.1 \pm 4.3$ & $66.1 \pm 6.4$ & 0.143 \\
\hline Follow-up left atrial diameter (mm) & $37.7 \pm 9.6$ & $39.8 \pm 18.2$ & 0.810 \\
\hline Follow-up Mitral E/E' ratio & $14.7 \pm 3.3$ & $16.1 \pm 5.7$ & 0.653 \\
\hline Follow-up tricuspid regurgitation, n (\%) & $7(43.2)$ & $16(24.2)$ & 0.203 \\
\hline Hemoglobin $(\mathrm{g} / \mathrm{dL})$ & $12.2 \pm 1.3$ & $12.3 \pm 2.1$ & 0.551 \\
\hline Creatinine (mg/dL) & $0.9 \pm 0.3$ & $1.1 \pm 0.9$ & 0.581 \\
\hline B-type natriuretic peptide (pg/mL) & $700.3 \pm 152.9$ & $329.4 \pm 332.4$ & 0.030 \\
\hline C-reactive protein (mg/L) & $1.9 \pm 0.7$ & $1.5 \pm 4.3$ & 0.127 \\
\hline
\end{tabular}

E/E' ratio, ratio of mitral velocity to early diastolic velocity of the mitral annulus.

Table 3. Multivariate analysis

\begin{tabular}{|c|c|c|c|c|}
\hline & $\begin{array}{l}\text { Patients with right } \\
\text { ventricular dysfunction }(n=16)\end{array}$ & $\begin{array}{l}\text { Patients without right } \\
\text { ventricular dysfunction }(n=66)\end{array}$ & $P$-value (univariate) & $P$-value (multivariate) \\
\hline Left ventricular ejection fraction (\%) & $57.5 \pm 10.8$ & $64.8 \pm 9.1$ & 0.050 & 0.178 \\
\hline B-type natriuretic peptide ( $\mathrm{pg} / \mathrm{mL}$ ) & $700.3 \pm 152.9$ & $329.4 \pm 332.4$ & 0.030 & 0.016 \\
\hline VVI pacing, $\mathrm{n}(\%)$ & $13(81.3)$ & $22(33.3)$ & 0.035 & 0.046 \\
\hline
\end{tabular}

and blood flow ${ }^{11}$ and adverse histopathological changes ${ }^{12}$ leads to long term pacing in canine hearts.

However, pacing induced LV dyssynchrony is unlikely the sole mechanistic explanation for significant reduction in left ventricle stroke volume. Some patients showed signs and symptoms of predominantly right side heart failure. We hypothesized that RV dysfunction might develop in patients with permanent pacemaker and play a role in reducing LV systolic function right side heart failure. Left ventricular functions are deranged in many conditions secondary to involvement of right ventricle. Isolated right ventricular infarction, atrial septal defect with right sided chronic volume over load and cor pulmonale result in altered LV diastolic and systolic function secondary to RV dysfunction. ${ }^{13-15}$ It is not obvious whether LV dysfunction is directly caused by RV dysfunction. Additional studies should be performed on temporal evolution of RV and LV function after pacemaker implantation. 
Many patients with permanent pacemaker have right side heart failure symptoms that leads to development of tricuspid regurgitation. ${ }^{16,17}$ In contrast, RV dysfunction showed no significant correlation with presence of meaningful tricuspid regurgitation in this study. This suggests that chronic RV pacing could lead to right heart failure without clinically significant $T R$ and associated RV dysfunction.

Serum BNP level usually reflect increased LV filling pressure resulting from LV systolic and diastolic dysfunction. In a particular study, correlation between BNP levels and indexes of pulmonary artery and right ventricular end-diastolic pressures was identified. ${ }^{18}$ In this study, serum BNP levels were significantly higher in patients with $\mathrm{RV}$ dysfunction suggesting the utility of this biomarker in early stage detection of RV dysfunction.

It is difficult to make exact measurement of RV function and various modalities have been proposed for this purpose. But in this study, we defined presence of RV dysfunction only using Doppler derived tricuspid lateral annular systolic velocity. Despite it is one of the most widely used methods, it is not sufficient to define RV function with one modality. And it was not clear that pacing induced LV dyssynchrony was associated with RV dysfunction in this study. Additional assessment should be performed for answering these questions.

\section{Conclusion}

In this study, significant proportion of patients showed chronic $\mathrm{RV}$ pacing induced RV dysfunction. RV dysfunction was associated with lower LV systolic function, higher BNP levels and VVI type pacemaker.

\section{Acknowledgements}

\section{None}

\section{References}

1) Delgado V, Tops LF, Trines SA, Zeppenfeld K, Marsan NA, Bertini M, Holman ER, Schalij MJ, Bax JJ. Acute effects of right ventricular apical pacing on left ventricular synchrony and mechanics. Circ Arrhythm Electrophysiol. 2009;2:135-145.
2) Fang F, Zhang Q, Chan JY, Razali O, Azlan H, Chan HC, Sanderson JE, Xie JM, Yu CM. Early pacing-induced systolic dyssynchrony is a strong predictor of left ventricular adverse remodeling: analysis from the Pacing to Avoid Cardiac Enlargement (PACE) trial. Int J Cardiol. 2013;168:723-728.

3) Curtis AB, Worley SJ, Adamson PB, Chung ES, Niazi I, Sherfesee L, Shinn T, Sutton MS; Biventricular versus Right Ventricular Pacing in Heart Failure Patients with Atrioventricular Block (BLOCK HF) Trial Investigators. Biventricular pacing for atrioventricular block and systolic dysfunction. $N$ Engl J Med. 2013;368:1585-1593.

4) Prinzen FW, Hunter WC, Wyman BT, McVeigh ER. Mapping of regional myocardial strain and work during ventricular pacing: experimental study using magnetic resonance imaging tagging. J Am Coll Cardiol. 1999;33:1735-1742.

5) Prinzen FW, Cheriex EC, Delhaas T, van Oosterhout MF, Arts T, Wellens HJ, Reneman RS. Asymmetric thickness of the left ventricular wall resulting from asynchronous electric activation: a study in dogs with ventricular pacing and in patients with left bundle branch block. Am Heart J. 1995;130:1045-1053.

6) Boerth RC, Covell JW. Mechanical performance and efficiency of the left ventricle during ventricular stimulation. Am J Physiol. 1971;221:1686-1691.

7) Burkhoff D, Oikawa RY, Sagawa K. Influence of pacing site on canine left ventricular contraction. Am J Physiol. 1986;251: H428435.

8) Karpawich PP, Mital S. Comparative left ventricular function following atrial, septal, and apical single chamber heart pacing in the young. Pacing Clin Electrophysiol. 1997;20:1983-1988.

9) Tse HF, Lau CP. Long-term effect of right ventricular pacing on myocardial perfusion and function. J Am Coll Cardiol. 1997;29:744-749.

10) Adomian GE, Beazell J. Myofibrillar disarray produced in normal hearts by chronic electrical pacing. Am Heart J. 1986;112:79-83.

11) Prinzen FW, Cheriex EC, Delhaas T, van Oosterhout MF, Arts T, Wellens HJ, Reneman RS. Asymmetric thickness of the left ventricular wall resulting from asynchronous electric activation: a study in dogs with ventricular pacing and in patients with left bundle branch block. Am Heart J. 1995;130:1045-1053.

12) Karpawich PP, Justice CD, Chang CH, Gause CY, Kuhns LR. Septal ventricular pacing in the immature canine heart: a new perspective. Am Heart J. 1991;121:837-833.

13) Weidemann RA, Mathay RA. Corpulmonale. In: Eugene Braunwald, editor. Heart Disease. 4th Edition. Philadelphia: Saunders; 1997, p1605.

14) Berisha S, Kastrati A, Goda A, Popa Y. Optimal value of filling pressure in the right side of the heart in acute right ventricular 
infarction. Br Heart J. 1990;63:98-102.

15) Lopez-Sendon J, Garcia-Fernandez MA, Coma-Canella I, Yangüela MM, Bañuelos F. Segmental right ventricular function after acute myocardial infarction: two-dimensional echocardiographic study in 63 patients. Am J Cardiol. 1983;51:390-396.

16) Fanari $Z$, Hammami $S$, Hammami MB, Hammami $S$, Shuraih $M$. The effects of right ventricular apical pacing with transvenous pacemaker and implantable cardioverter defibrillator on mitral and tricuspid regurgitation. J Electrocardiol. 2015;48:791-797.

17) Sadreddini M, Haroun MJ, Buikema L, Morillo C, Ribas S,
Divakaramenon S, Connolly SJ, Nieuwlaat R, Lonn EM, Healey JS, Dokainish H. Tricuspid valve regurgitation following temporary or permanent endocardial lead insertion, and the impact of cardiac resynchronization therapy. Open Cardiovasc Med J. 2014;8:113-120.

18) Nagaya N, Nishikimi T, Okano Y, Uematsu M, Satoh T, Kyotani S, Kuribayashi S, Hamada S, Kakishita M, Nakanishi N, Takamiya M, Kunieda T, Matsuo H, Kangawa K. Plasma brain natriuretic peptide levels increase in proportion to the extent of right ventricular dysfunction in pulmonary hypertension. J Am Coll Cardiol. 1998;31:202-208. 